\title{
Insights into the growth of newly formed particles in a subtropical urban environment
}

\author{
F. Salimi ${ }^{1, \text { a }}$, L. R. Crilley ${ }^{1, b}$, S. Stevanovic ${ }^{1}$, Z. Ristovski ${ }^{1}$, M. Mazaheri ${ }^{1}$, C. He ${ }^{1}$, G. Johnson ${ }^{1}$, G. Ayoko ${ }^{1}$, and \\ L. Morawska ${ }^{1}$ \\ ${ }^{1}$ International Laboratory for Air Quality and Health, Queensland University of Technology, GPO Box 2434, \\ Brisbane QLD, 4001, Australia \\ ${ }^{a}$ now at: Menzies Research Institute, University of Tasmania, Hobart, Tasmania, Australia \\ ${ }^{b}$ now at: School of Geography, Earth and Environmental Science, University of Birmingham, Edgbaston, \\ Birmingham, B15 2TT, UK
}

Correspondence to: L. Morawska (1.morawska@qut.edu.au)

Received: 3 September 2014 - Published in Atmos. Chem. Phys. Discuss.: 11 November 2014

Revised: 11 November 2015 - Accepted: 17 November 2015 - Published: 7 December 2015

\begin{abstract}
The role of different chemical compounds, particularly organics, involved in the new particle formation (NPF) and its consequent growth are not fully understood. Therefore, this study was conducted to investigate the chemical composition of aerosol particles during NPF events in an urban subtropical environment. Aerosol chemical composition was measured along with particle number size distribution (PNSD) and several other air quality parameters at five sites across an urban subtropical environment. An Aerodyne compact Time-of-Flight Aerosol Mass Spectrometer (c-ToF-AMS) and a TSI Scanning Mobility Particle Sizer (SMPS) measured aerosol chemical composition (particles above $50 \mathrm{~nm}$ in vacuum aerodynamic diameter) and PNSD (particles within 9-414 $\mathrm{nm}$ in mobility diameter), respectively. Five NPF events, with growth rates in the range 3.3$4.6 \mathrm{~nm}$, were detected at two of the sites. The NPF events happened on relatively warmer days with lower condensation sink (CS). Temporal percent fractions of organics increased after the particles grew enough to have a significant contribution to particle volume, while the mass fraction of ammonium and sulfate decreased. This uncovered the important role of organics in the growth of newly formed particles. Three organic markers, factors $f_{43}, f_{44}$ and $f_{57}$, were calculated and the $f_{44}$ vs. $f_{43}$ trends were compared between nucleation and non-nucleation days. K-means cluster analysis was performed on $f_{44}$ vs. $f_{43}$ data and it was found that they follow different patterns on nucleation days compared to non-nucleation days, whereby $f_{43}$ decreased for
\end{abstract}

vehicle-emission-generated particles, while both $f_{44}$ and $f_{43}$ decreased for NPF-generated particles. It was found for the first time that vehicle-generated and newly formed particles cluster in different locations on $f_{44}$ vs. $f_{43}$ plot, and this finding can be potentially used as a tool for source apportionment of measured particles.

\section{Introduction}

Aerosol particles affect the Earth's climate, air quality and public health, both directly and indirectly (e.g. Stevens and Feingold, 2009; Lohmann and Feichter, 2005; Pope II and Dockery, 2006). Knowledge about their formation, transformation and physical/chemical properties helps in understanding their effects on climate and human health. New particle formation (NPF; also known as nucleation) events have been observed in different locations, including coastal, forested, rural and urban areas (O'Dowd et al., 2002; Kulmala et al., 2007; Petäjä et al., 2007; Stanier et al., 2004; Woo et al., 2001;S alma et al., 2010; Cheung et al., 2010; Mejía and Morawska, 2009; Modini et al., 2009), and these events are one of the main sources of ultrafine particles (UFPs; particles smaller than $100 \mathrm{~nm}$ ), in addition to combustion-emitted particles (Morawska et al., 2009). The significant increase in the number of UFPs after NPF events can potentially cause adverse effects on human health, given the increasing evidence of the toxicity of UFPs and their role in human mor- 
tality and morbidity (Donaldson et al., 2002; WHO, 2005; Ning et al., 2003).

Over the past years, the traditional view of the NPF has evolved in light of the recent breakthroughs in this field. The main findings leading to the current understanding of NPF events were observations and theoretical prediction of molecular clusters and their size-dependent growth via nanoKohler-type processes (Kulmala et al., 2007, 2013, 2004). It is now understood that this process includes the following steps: (I) production of low and extremely low volatile vapours as a result of chemical reaction in the gas phase; (II) clustering; (III) nucleation; (IV) activation of clusters by a different group of vapours; and (V) multicomponent condensation growth of the activated clusters (Ehn et al., 2014; Riccobono et al., 2014; Kulmala et al., 2014a, b).

The chemical composition of UFPs during NPF events in urban environments have been investigated in only a handful of studies as it was thought that these events tend to happen more in pristine air. However, NPF events have been observed frequently in Brisbane, an urban area in eastern Australia, and were associated with precursors emitted from traffic and solar radiation (Cheung et al., 2010). Cheung et al. (2010) characterised the evolution of particle number size distribution (PNSD) in Brisbane and found 65 nucleation events over a 1-year period, with an average particle growth rate of $4.6\left(\mathrm{~nm} \mathrm{~h}^{-1}\right)$. Leigh et al. (2014) found ammonium and sulfate as the dominant species on particle formation days in a short-term study based on measurements at a fixed site. More studies need to be carried out, particularly in less investigated areas, using direct measurement techniques, and including comprehensive and advanced analysis, in order to determine the species involved in NPF events and the nature of their contribution. To address this gap in knowledge, the main aim of this study was to determine the role of chemical species in NPF events growth process in a subtropical urban environment.

\section{Materials and methods}

\subsection{Background}

This study was performed as part of the "Ultrafine Particles from Traffic Emissions and Children's Health" project (UPTECH; Salimi et al., 2013). Air quality measurements were conducted for two consecutive weeks at each of 25 sites across the Brisbane Metropolitan Area, in Australia, during the period October 2010 to August 2012. Chemical composition of the aerosol particles was monitored in real time at five sites, referred to as s1, s4, s11, s12 and s25.

\subsection{Instrumentation}

Meteorological parameters including wind speed/direction, relative humidity and solar radiation were measured using a "Monitor Sensor" weather station. A TSI Scanning Mobility
Particle Sizer (SMPS) measured PNSD within the size range $9-414 \mathrm{~nm}$. The SMPS system consisted of a TSI 3071 Differential Mobility Analyser (DMA) and a TSI 3782 water-based Condensation Particle Counter (CPC). Particle size detection accuracy of the SMPS system was calibrated at the start of measurements at each site using polystyrene latex (PSL) particles. In addition, the system sheath and aerosol flow rate were checked every second day. The measured PNSD data were corrected for diffusion loss inside the system and sampling tube. Further information regarding the SMPS's operating conditions and calibration can be found in Salimi et al. (2014). An Aerodyne compact Time-of-Flight Aerosol Mass Spectrometer (c-ToF-AMS) was deployed to monitor the chemical composition of aerosol particles in the $\mathrm{PM}_{1}$ fraction in real time. A detailed description of the sampling method and c-ToF-AMS operation can be found in Crilley et al. (2013). Briefly, the c-ToF-AMS was housed in a vacant room at each site and sampled for 2-3 weeks. The sampling interval was $5 \mathrm{~min}$, alternating equally between particle time of flight and mass spectrometer modes. The instrument was calibrated for both ion efficiency and particle size at the beginning of measurements at each site, and ion efficiency calibration was also performed in the middle and at the end of measurement campaigns at each site. All calibrations were performed according to the standard procedures proposed in the literature (Drewnick et al., 2005; Jayne et al., 2000; Jimenez et al., 2003c). Solar radiation and other meteorological parameters were measured by a Monitor Sensors $\mu$ Smart Series weather station, a TSI 3781 water-based CPC was used for particle number concentration (PNC) measurements, and a TSI DustTrak measured particle mass concentration $\left(\mathrm{PM}_{2.5}\right.$ and $\left.\mathrm{PM}_{10}\right)$.

\subsection{Data analysis}

Characterisation of new particle formation events: NPF events were identified and classified using the procedure developed by Dal Maso et al. (2005). PNSD data were analysed to identify a distinct new mode of particles in the nucleation mode size range (particles with diameter less than $30 \mathrm{~nm}$ ). If the mode grew in size and was persistent for more than $1 \mathrm{~h}$, it was assigned as a NPF event. Once identified, the growth rates of the nucleation events were calculated following the procedure described in Creamean et al. (2011).

\subsubsection{Condensation sink}

The surface area of aerosol particles available for condensation can be estimated by the condensation sink (CS) parameter which is calculated from the measured PNSD. The CS determines the rate of condensation of gaseous molecules on pre-existing particles and is a function of PNSD (Pirjola et al., 1999; Lehtinen et al., 2003). CS, with unit $\mathrm{s}^{-1}$, was cal- 
culated using the following formula (Lehtinen et al., 2003):

$\mathrm{CS}=2 \pi D \int_{0}^{\infty} d_{\mathrm{p}} \beta_{M}\left(d_{\mathrm{p}}\right) n\left(d_{\mathrm{p}}\right) d d_{\mathrm{p}}=2 \pi D \sum_{i}^{\beta_{M_{i}} d_{\mathrm{p}, i} N_{i}}$,

where $D$ is the diffusion coefficient, $d_{\mathrm{p}}$ is the particle diameter, $N_{i}$ is the concentration of particles and $\beta_{M}$ can be expressed as (Fuks et al., 1971)

$\beta_{M}=\frac{K n+1}{0.377 K n+1+\frac{4}{3} \alpha^{-1} K n^{2}+\frac{4}{3} \alpha^{-1} K n}$,

where $\alpha$ is the sticking coefficient and is assumed to be 1 (Clement et al., 1996) and $K n$ is the Knudsen number, which is equal to $\frac{2 \lambda_{v}}{d_{\mathrm{p}}}$. The mean free path $\left(\lambda_{v}\right)$ is a function of pressure and temperature and can be calculated using the following formula (Willeke, 1976):

$\lambda_{v}=\lambda_{o}\left(\frac{101}{p}\right)\left(\frac{T}{296.2}\right)\left(\frac{\left(1+\frac{110}{296.2}\right)}{\left(1+\frac{110}{T}\right)}\right)$,

where $P$ is in $\mathrm{kPa}$ and $T$ in kelvin. $\lambda_{o}=0.039 \mu \mathrm{m}$, which is the mean free path of $\mathrm{H}_{2} \mathrm{SO}_{4}$ at standard conditions (Bae et al., 2010). CSs were calculated using the above-mentioned procedure on the PNSD data.

\subsubsection{Particle size}

Due to the difference in detection limit between the two instruments $\left(D_{\mathrm{va}}=50 \mathrm{~nm}\right.$ for AMS and $D_{\mathrm{m}}=10 \mathrm{~nm}$ for SMPS), measurement of the mass distribution for the smallest particles detected during each nucleation was delayed for the AMS in order for particles to grow to the detectable size. Ratio of mobility diameter $\left(D_{\mathrm{m}}\right)$, measured by the SMPS, to vacuum aerodynamic diameter $\left(D_{\mathrm{va}}\right)$ is a function of size, composition, shape and relative humidity for ambient particles. This ratio can be simplified to be equal to particle density, assuming that particles are spherical (Jimenez et al., 2003a). The newly formed particles were assumed to have the density of around $1.8 \mathrm{~g} \mathrm{~cm}^{-3}$ and, therefore, $D_{\mathrm{m}} / D_{\mathrm{va}}=1.8$ for newly formed particles (Zhang et al., 2004). Therefore, the AMS's lowest detection limit will be equivalent to a $D_{\mathrm{m}}=30 \mathrm{~nm}$.

\subsubsection{Particle chemical composition}

Concentrations of sulfate, nitrate, organics and ammonium were measured by a c-ToF-AMS, as these have been identified as the main contributing species to the NPF events and subsequent particulate growth in literature (Zhang et al., 2004). These data were processed and analysed using Squirrel v1.51 in Igor Pro v6.22. The organic aerosol (OA) can be divided into oxygenated OA (OOA) and hydrocarbonlike OA (HOA), based upon key $m / z$ ions that have been shown to be surrogates for the different components. OOA can be separated further into low-volatility OOA (LV-OOA) and semi-volatile (SV-OOA). Two main ions, $m / z 44\left(\mathrm{CO}_{2}^{+}\right)$ and $m / z 43$ (mostly $\mathrm{C}_{2} \mathrm{H}_{3} \mathrm{O}^{+}$), can characterise the evolution of $\mathrm{OA}$ in the atmosphere ( $\mathrm{Ng}$ et al., 2010b). The ratios of $m / z 44$ and $m / z 43$ to total organic signal ( $f_{44}$ and $f_{43}$, respectively) indicate the degree of oxidation of $\mathrm{OA}$, since the SV-OOA component spectra have a lower $f_{44}$ and higher $f_{43}$ compared to LV-OOA. OA has been shown to occupy a triangular region of the $f_{44}$ vs. $f_{43}$ plot with younger OA occupying the lower part of the triangle, while more oxidised and subsequently more aged OAs are concentrated in the upper part (Ng et al., 2010b, 2011). Therefore, $f_{43}$ and $f_{44}$ were calculated and plotted against each other to determine the type and evolution of OA during NPF events. $m / z 57$ ions have been shown to be a tracer of HOA (primary organics from combustion sources) ( $\mathrm{Ng}$ et al., 2010a), and therefore $f_{57}$ was calculated to investigate the OA that originated from vehicle emissions.

\subsubsection{LOESS smoothing}

In order to better understand the trends and patterns of the data, LOESS technique as a locally weighted polynomial regression smoothing method was selected and applied to the data. The resulting smooth functions, and their $95 \%$ confidence intervals, indicate the trends of the relevant data throughout the paper (Cleveland and Devlin, 1988).

\subsubsection{K-means clustering}

This clustering algorithm minimises the within-cluster sum of squares in order to divide $M$ observations with $N$ dimensions into K clusters (Hartigan and Wong, 1979). A common method of choosing the number of clusters is to compare visually a measure of error, such as sum of squared error (SSE), with sequential number of clusters by plotting the measure of error on $y$ axis and the number of clusters on $x$ axis (Everitt et al., 2010). Optimum number of clusters is the point at which the measure of error flattens and forms an elbow. The abovementioned clustering technique was applied to the $f_{44}$ and $f_{43}$ to assess the possible clustering for days with and without nucleation.

\section{Results and discussion}

\subsection{Identified new particle formations}

PNSD data were available for $6,18,11,13$ and 8 days in $\mathrm{s} 1$, s4, s11, s12 and s25 respectively. After the analysis of PNSD measured at five sites, five NPF events were detected, where three events were observed in s12 and two in s25, while no events were observed at s1, s4 and s11. Therefore, we focused only on s12 and s25, for which the NPF growth rates varied from 3.3 to $4.6\left(\mathrm{~nm} \mathrm{~h}^{-1}\right)$ (Table 1$)$. 
Table 1. Duration of each nucleation event as well as their average growth rates. Growth rates were calculated by a linear fit from 9 to $20 \mathrm{~nm}$.

\begin{tabular}{lllr}
\hline Site & Start of event & End of event & $\begin{array}{r}\text { Growth rate } \\
\left(\mathrm{nm} \mathrm{h}^{-1}\right)\end{array}$ \\
\hline s12 & $12 / 08 / 2011,11: 00$ & $13 / 08 / 2011,05: 00$ & 3.9 \\
s12 & $13 / 08 / 2011,12: 30$ & $14 / 08 / 2011,06: 20$ & 4.6 \\
s12 & $14 / 08 / 2011,15: 20$ & $15 / 08 / 2011,06: 00$ & 3.3 \\
s25 & $25 / 08 / 2012,12: 24$ & $26 / 08 / 2012,02: 14$ & 4.3 \\
s25 & $26 / 08 / 2012,12: 00$ & $27 / 08 / 2012,01: 00$ & 3.8 \\
\hline
\end{tabular}

Figure 1 summarises the average solar radiation, relative humidity, temperature and CS calculated using LOESS method for days with NPF events (nucleation days), as well as for the days where no NPF events were observed (nonnucleation days) at s12 and s25. Nucleation days had higher solar radiation intensity compared to non-nucleation days at s25 while opposite trend was observed at s12. Nucleation days had a slightly higher temperature compared to nonnucleation days at both sites. Higher relative humidity was observed on nucleation days compared to non-nucleation days at s12, whereas opposite trend was observed at S25. The wind speed and direction have not been plotted as they did not show a typical trend during the nucleation and nonnucleation days. CS was found to be lower on nucleation days compared to non-nucleation days, about $2 \mathrm{~h}$ before the start of nucleation at both sites. Similar trends have been observed in other studies (Salma et al., 2011; Hussein et al., 2008). CS is a measure of the available surface area for condensation of vapours, as well as for the scavenging of particle clusters. A small CS is favourable for nucleation as it produces less surface area for vapours and newly formed clusters, in agreement with the observations in Fig. 1.

Figure 2 illustrates the average mass concentration of organics, nitrate, sulfate and ammonium during nucleation and non-nucleation days at s12 and s25. Mass concentration of organics and nitrate followed relatively the same trend through the day until 16:00-17:00 AEST (6-7 $\mathrm{h}$ after the start of the NPF event) at s12 and s25.

However, mass concentration of organics and nitrate increased dramatically between 15:00 and 22:00 on nucleation days, at higher rate compared to non-nucleation days at s12, and the same trend was observed at $\mathrm{s} 25$, with an hour delay in the increase of the mass concentration of organics and nitrate. At s25, sulfate and ammonium mass concentration started to increase at 12:00, reached a peak and decreased subsequently; however, a significant increase was observed around 16:00.

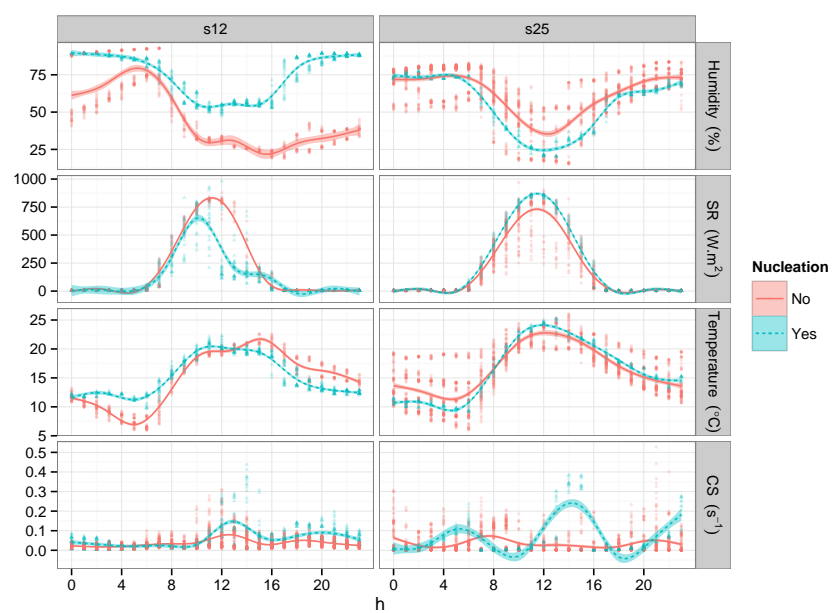

Figure 1. Average diurnal pattern of solar radiation (SR), humidity, temperature and condensation sink (CS) as well as the measured data on nucleation and non-nucleation day at s12 and s25. Shaded areas represent the $95 \%$ confidence interval in the mean. Data include 5 and 51 nucleation and non-nucleation days respectively.

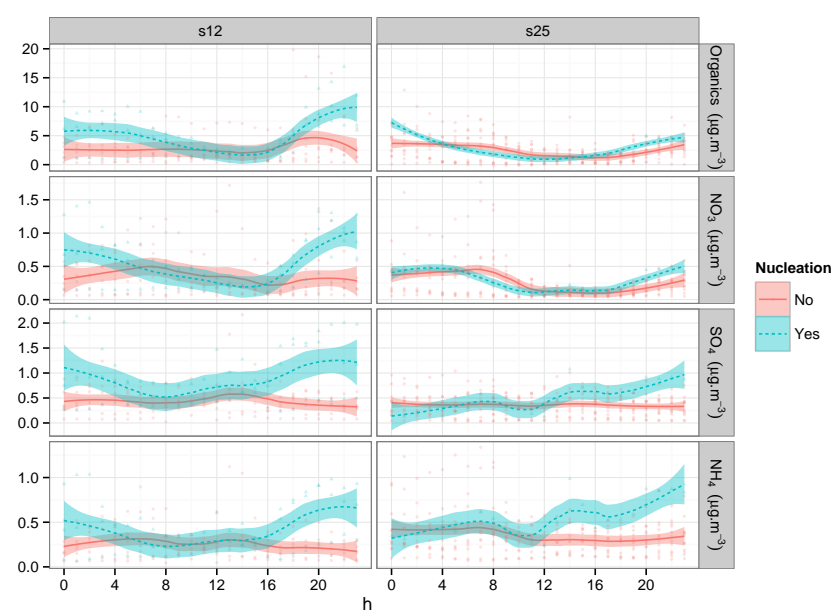

Figure 2. Average diurnal pattern of organics, nitrate, sulfate and ammonium concentrations as well as the measured data on nucleation and non-nucleation days at s12 and S25. Shaded areas represent the $95 \%$ confidence interval in the mean. Data include 5 and 51 nucleation and non-nucleation days respectively.

\subsection{Evolution of chemical composition of newly formed particles}

The analysis and interpretation of the chemical composition of the newly formed particles focuses mostly on the particles in the growth phase due to the lowest detection limit of the c-ToF-AMS, which does not permit seeing them in the formation phase. Particle volume distribution (PVD) was calculated from the PNSD data as it is a better measure for comparison with the mass.

It has been previously determined in the literature that the main contributing species to NPF events and subsequent par- 


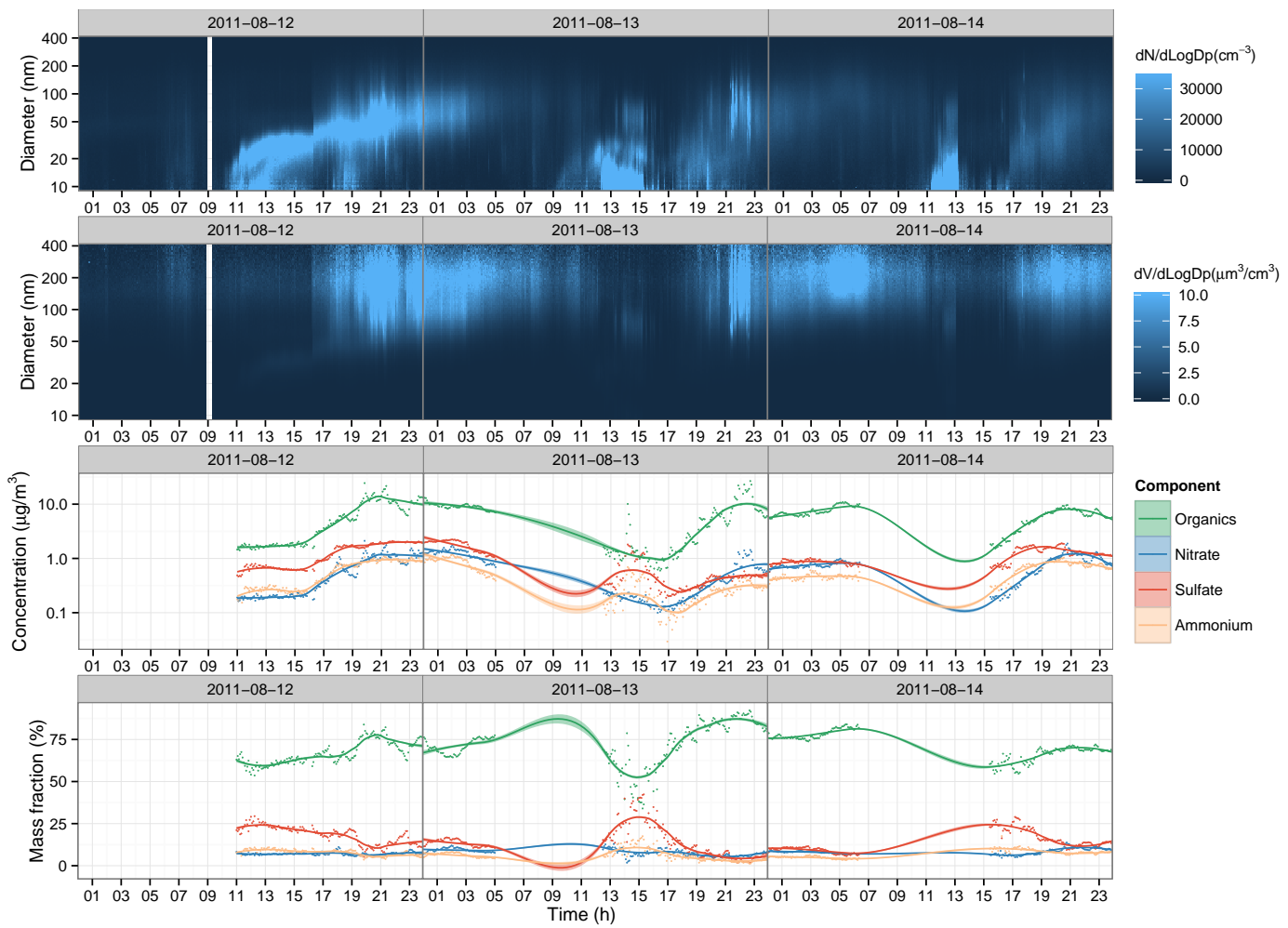

Figure 3. Time series of the particle number/volume size distributions (top two graphs) and mass concentration of particle species and their fraction to the total (bottom two graphs) at s12. Solid lines are calculated using LOESS smoothing technique, and the shaded areas represent the $95 \%$ confidence interval.

ticulate growth are sulfate, nitrate, organics and ammonium (Zhang et al., 2004). Therefore, the percent fractions of each of these chemical species were calculated by dividing the mass concentration of each chemical species by the total (sulfate + nitrate + ammonium + organics).

Figure 3 illustrates the evolution of PNSD, PVD, and mass concentration of chemical species (organics, nitrate, sulfate and ammonium) during the three consecutive NPF events at s12. In general, mass concentration of the aerosol species followed the evolution of particle volume distribution as expected. Ammonium, sulfate and nitrate mass fractions peaked just before the particle volumes increase due to the growth of newly formed particles. However, organic mass fraction followed the opposite trend, with a significant rise after the increase in particles volume due to the growth of new particles. In other words, the fraction of organics increased and the fraction of ammonium, sulfate and nitrate decreased when the newly formed particles grew enough to dominate the particle volume. This shows the import contribution of organics to the growth of newly formed particles.

Time series of PNSD and mass concentration of particle species during two NPF events happening on two consecutive days at s25 are illustrated in Fig. 4. The mass concentrations of the chemical species and their fractions followed similar trends as the ones at s12. At s12, the magnitude of mass fractions changed from almost 50,30, 10 and $10 \%$ before the nucleation to $70,20,6$ and $4 \%$ after the event for organics, sulfate, ammonium and nitrate respectively. At s25, the changes in mass fractions were more dramatic as they changed from $40,25,25$ and $10 \%$ before the event to 85,5 , 5 and $5 \%$ after the nucleation occurred.

\subsection{Role of organics}

As indicated in the previous section, five NPF events were observed at $\mathrm{s} 12$ and the contribution of organics to the growth of newly formed particles was high; therefore, further data analyses regarding the role of organics were performed. Firstly, $f_{43}$ and $f_{44}$ were calculated for the total chemical mass data on nucleation days and non-nucleation days. $f_{44}$ was plotted against $f_{43}$ at each hour of the day, as well as the triangle space proposed by Ng et al. (2010b) (Fig. 5). During the non-nucleation days, the OA was concentrated in the middle and right border of the triangular region, which is the beginning of the LV-OOA region. As expected, the $f_{44}$ decreased during morning and afternoon rush hours, as the particles were younger and less oxidised, while $f_{43}$ remained almost unchanged during the day.

During the nucleation days, several hours after the start of nucleation, when the particles grew enough to have significant effect on the total signal, $f_{44}$ and $f_{43}$ both decreased 


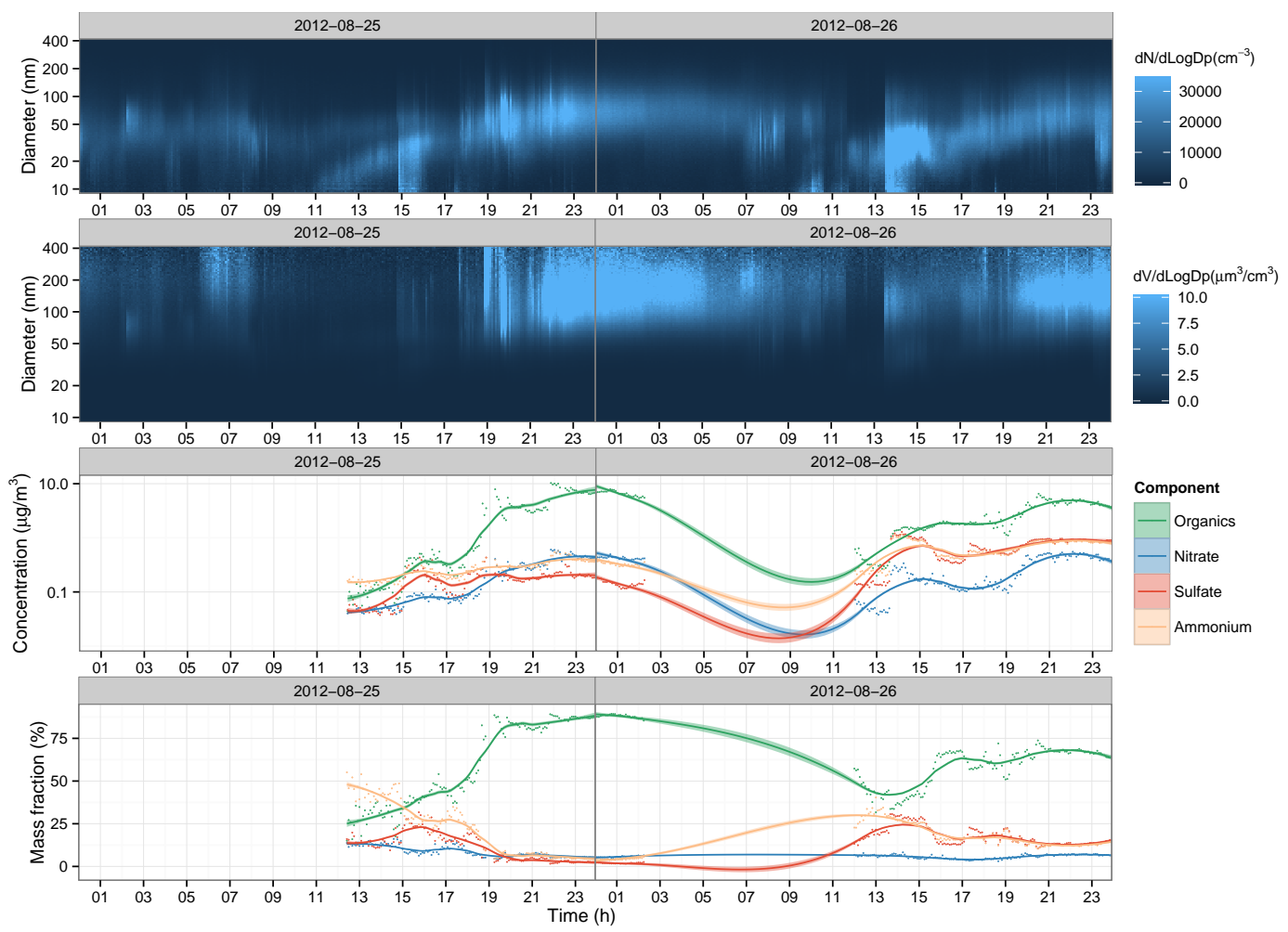

Figure 4. Time series of the particle number/volume size distributions (top two graphs) and mass concentration of particle species and their fraction to the total (bottom two graphs) at s25. Solid lines are calculated using LOESS smoothing technique, and the shaded areas represent the $95 \%$ confidence interval.

and the aerosol components reached the bottom left side of the triangular region. It is expected that the particles originating from nucleation events cluster somewhere at top of the triangle; however, as the particles measured in our study originated from nucleation events and primary vehicle emissions, they clustered at the middle left-hand side of the triangle. The above-mentioned visual inspection of the figure revealed potential clustering on the graph during nucleation and non-nucleation days.

In order to assess the possible different clustering of $f_{44}$ vs. $f_{43}$ for nucleation days compared to non-nucleation days, $\mathrm{K}$-means clustering technique was applied on the $f_{43}$ and $f_{44}$ data. A period between 15:00 and 17:00 was selected for this purpose as this was the initial stage where the newly formed particles grew enough to have significant contribution to the total signal. In order to find the optimum number of clusters, SSE was plotted against the sequential number of clusters; five was the number of clusters found to be appropriate as it was located at the elbow in the plot (Fig. 6).

The five identified clusters as well as their $95 \%$ confidence ellipse are illustrated in Fig. 7a; $93 \%$ of the data measured in nucleation days were in clusters $3-5(54,15$ and $24 \%$ in clusters 3,4 and 5 respectively) while clusters 1 and 2 contained $77 \%$ of the data measured in non-nucleation days (Fig. 7). In addition, cluster 1 and 5 contained less than $1 \%$ of nucleation and non-nucleation days respectively. These show a distinct clustering on $f_{44}$ vs. $f_{43}$ for nucleation days compared to non-nucleation days and indicate a potential application of $f_{44}$ vs. $f_{43}$ plot for identification of the newly formed particles.

It has been reported in the literature that $f_{57}$ is associated with combustion-generated primary organics (Canagaratna et al., 2004; Jimenez et al., 2003b). $f_{57}$ was calculated and its diurnal variation was modelled using a LOESS smoothing model. The measured data and their smoothed average showed that $f_{57}$ followed exactly the same trend on nucleation and non-nucleation days, with an increase during the morning and afternoon rush hours (Fig. 8). All nonnucleation days did not have exactly the same meteorological conditions, but the effects of their variation on $f_{57}$ were minimal.

\section{Summary and conclusions}

In summary, PNSD, chemical composition and meteorological parameters were measured at five sites across the Brisbane Metropolitan Area. Five NPF events, with growth rates ranging from 3.3 to $4.6 \mathrm{~nm} \mathrm{~h}^{-1}$, were observed at two of the five sites, and the NPF events happened on days with lower CS and higher temperature than non-event days. Higher sul- 

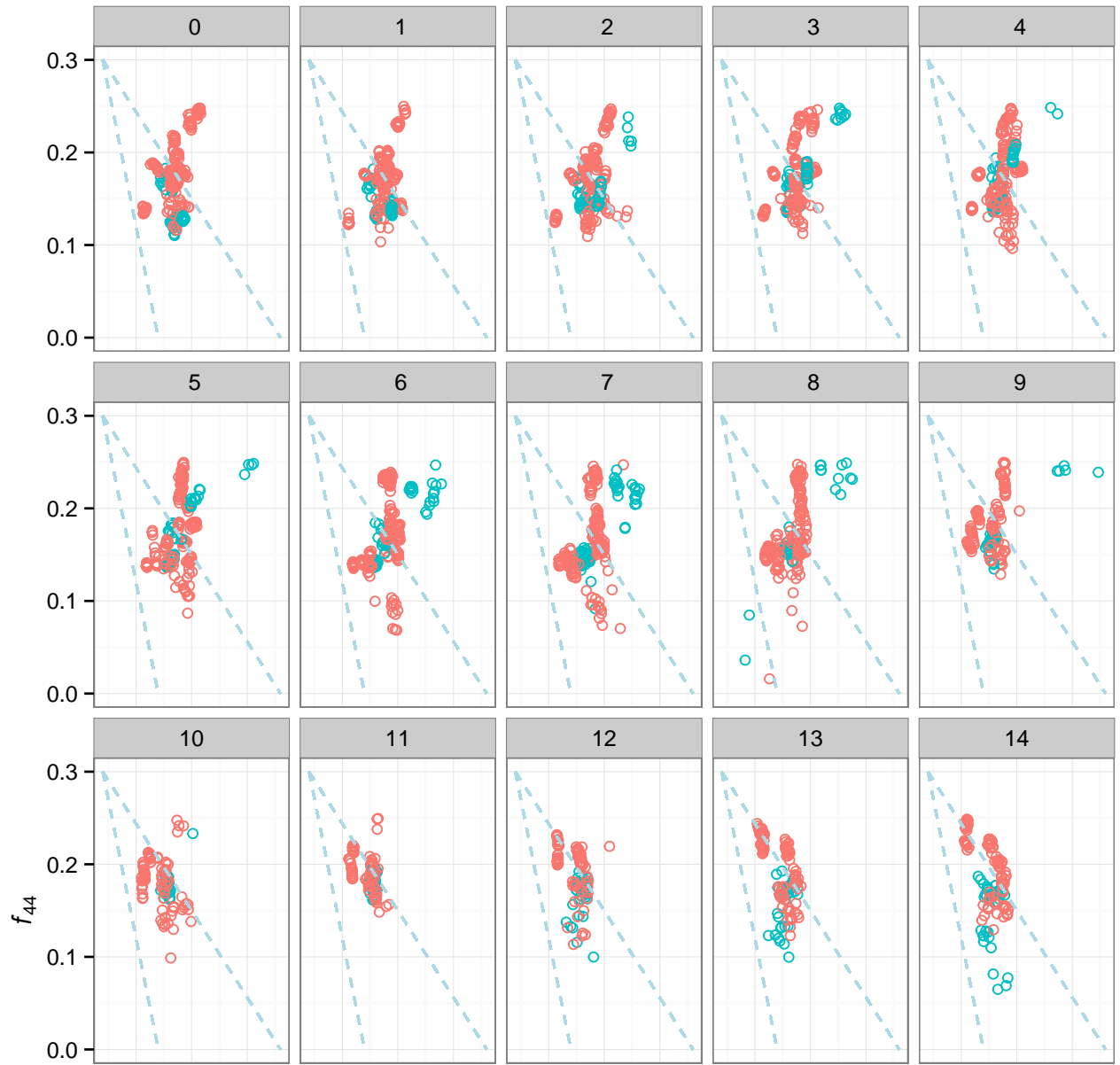

Nucleation
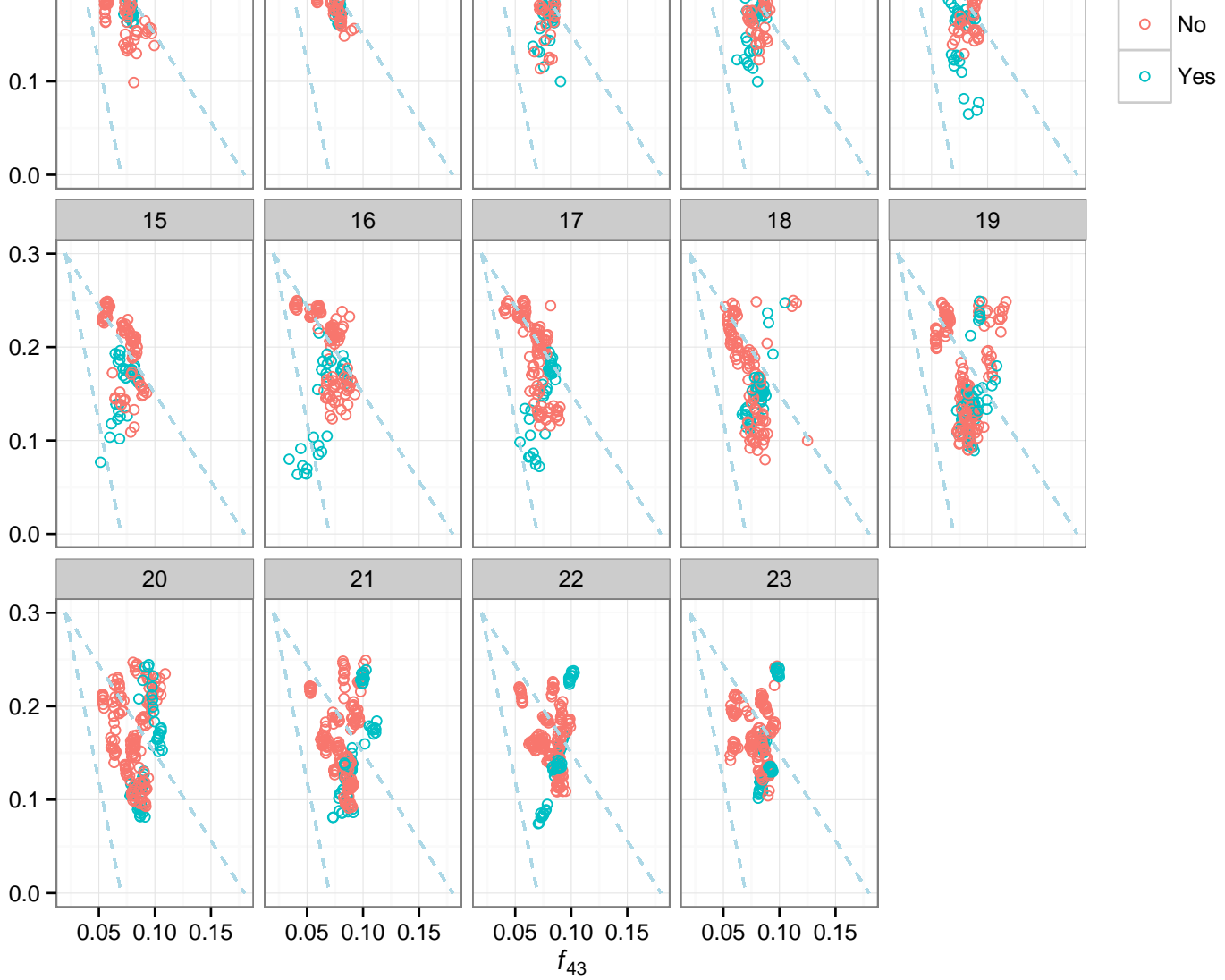

Figure 5. $f_{44}$ vs. $f_{43}$ at each hour of the day for all data measured during nucleation and non-nucleation days. The triangle from Ng et al. (2010b) is drawn as a visual aid. Within the period of $15-17$, the newly formed particles grew enough to have significant contribution to total signal. Data include 5 and 51 nucleation and non-nucleation days respectively. 


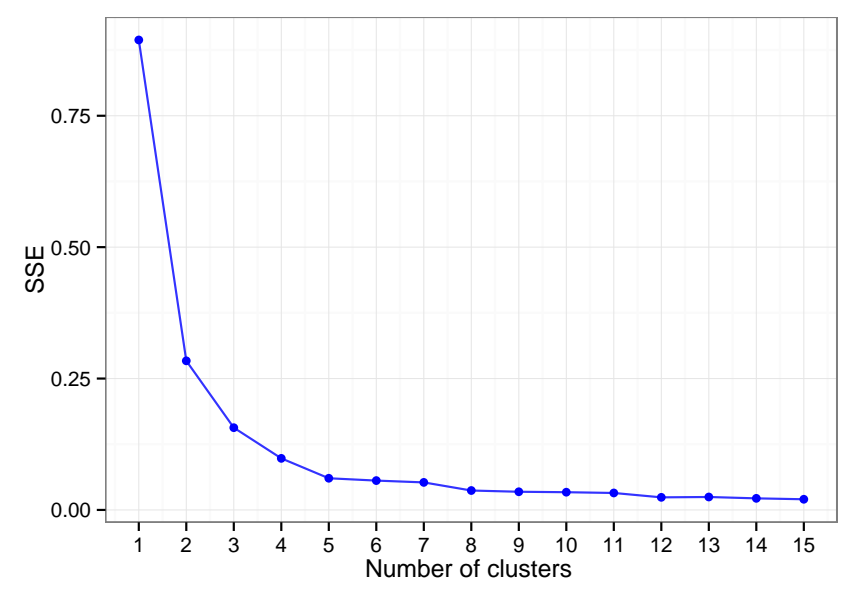

Figure 6. SSE versus the number of clusters. The sharp decrease in SSE stops at five clusters forming an elbow.

(a)

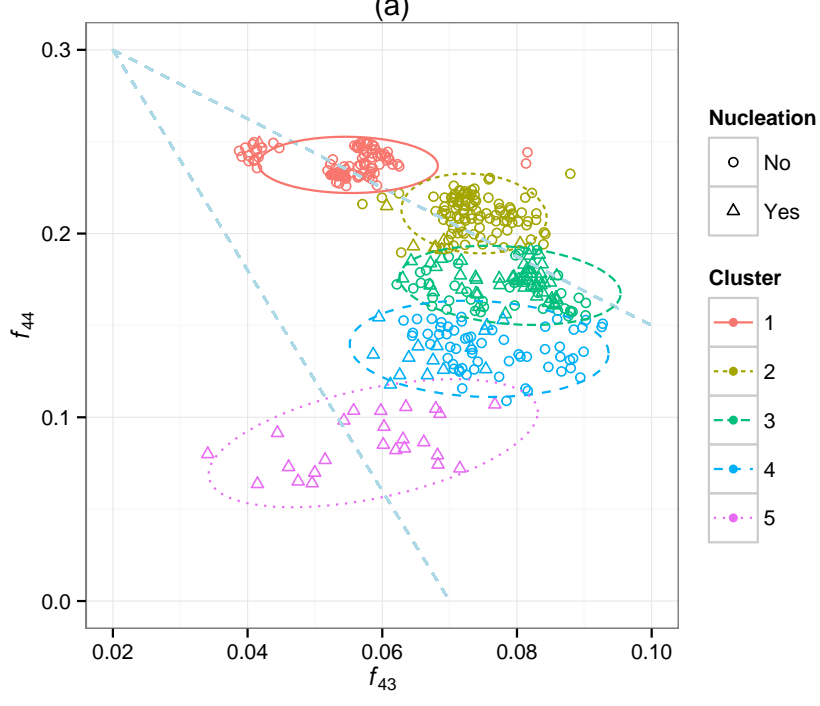

(b)

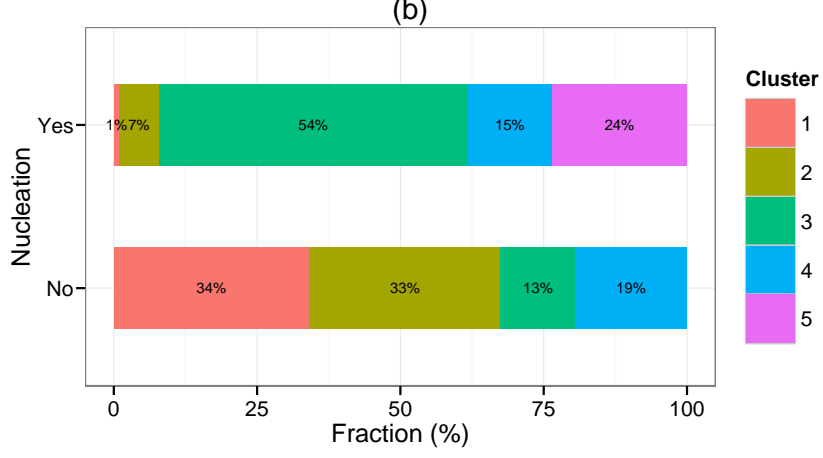

Figure 7. The $f_{44}$ vs. $f_{43}$ plot for nucleation days and nonnucleation days with the five clusters and their $95 \%$ confidence epsilon (a). The contributing proportion of each cluster to the total for nucleation and non-nucleation days (b). The triangle from $\mathrm{Ng}$ et al. (2010b) is drawn as a visual aid.

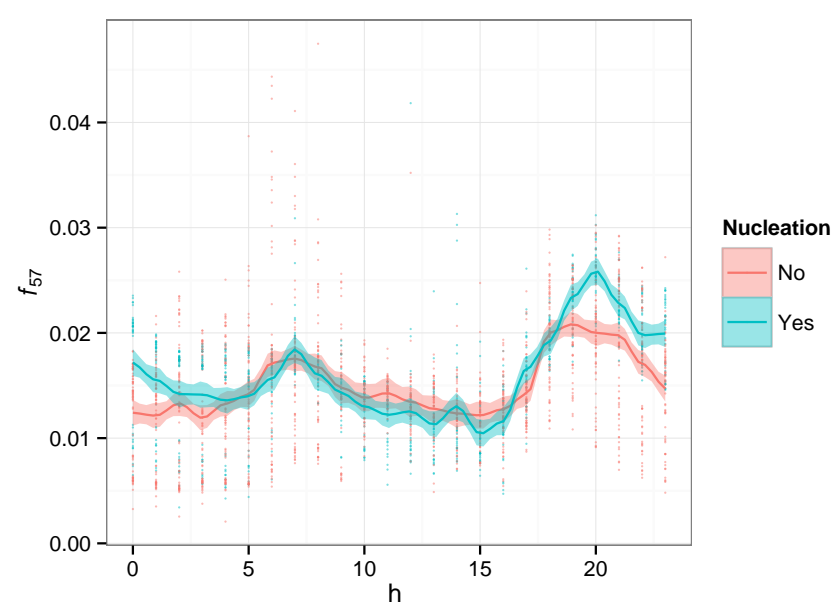

Figure 8. Diurnal variation of the $f_{57}$ during the nucleation and non-nucleation days. Solid lines have been calculated using the LOESS smoothing method, and the shaded areas represent the $95 \%$ confidence interval. Data include 5 and 51 nucleation and nonnucleation days. The data include weekdays and weekend as no exclusions were applied to increase the statistical power.

fate, nitrate, ammonium and organics were observed on nucleation days compared with days when no nucleation was observed. Percent fractions of nitrate, sulfate, ammonium and organic chemical species were calculated and their diurnal trends were modelled using LOESS. Ammonium, sulfate and nitrate mass fractions increased before the newly formed particles grew enough to have a significant contribution to the particle volume, peaked around that time and decreased after that. Conversely, the organics percent fraction increased significantly after the contribution of new particles to total volume, indicating the important role of organics in the growth phase of NPF events. $f_{44}$ and $f_{43}$ were analysed to investigate the role of organics more in depth, as the $f_{44}$ vs. $f_{43}$ would reveal information regarding the level of oxidation and volatility of OOA. $f_{43}$ and $f_{44}$ both decreased after the start of nucleation, while $f_{44}$ decreased only in case of particles generated from vehicle emission. K-means clustering analysis revealed that the aerosol particles generated by vehicle emissions and NPF events clustered in different locations on the $f_{44}$ vs. $f_{43}$ plot. This determined the potential application of the $f_{44}$ vs $f_{43}$ plot for identification of the source(s) and transformation of the OOA components as they clearly followed different patterns. However, it should be noted that the analyses were based on only five NPF events and the results may not be a general rule.

Acknowledgements. This work was supported by the Australian Research Council (ARC), QLD Department of Transport and Main Roads (DTMR) and QLD Department of Education, Training and Employment (DETE) through Linkage Grant LP0990134. Our particular thanks go to R. Fletcher (DTMR) and B. Robertson (DETE) for their vision regarding the importance of this work. We 
would also like to thank G. Marks, P. Robinson, K. Mengersen, R. Jayaratne, S. Low Choy, G. Williams, W. Ezz, S. Clifford, M. Mokhtar, N. Mishra, R. Laiman, L. Guo, C. Duchaine, H. Salonen, X. Ling, J. Davies, L. Leontjew Toms, F. Fuoco, A. Cortes, B. Toelle, A. Quinones, P. Kidd and E. Belousova, M. Falk, F. Fatokun, J. Mejia, D. Keogh, T. Salthammer, R. Appleby and C. Labbe for their contribution to the UPTECH project.

Edited by: W. Birmili

\section{References}

Bae, M.-S., Schwab, J. J., Hogrefe, O., Frank, B. P., Lala, G. G., and Demerjian, K. L.: Characteristics of size distributions at urban and rural locations in New York, Atmos. Chem. Phys., 10, 45214535, doi:10.5194/acp-10-4521-2010, 2010.

Canagaratna, M. R., Jayne, J. T., Ghertner, D. A., Herndon, S., Shi, Q., Jimenez, J. L., Silva, P. J., Williams, P., Lanni, T., and Drewnick, F.: Chase studies of particulate emissions from in-use New York City vehicles, Aerosol Sci. Tech., 38, 555-573, 2004.

Cheung, H. C., Morawska, L., and Ristovski, Z. D.: Observation of new particle formation in subtropical urban environment, Atmos. Chem. Phys., 11, 3823-3833, doi:10.5194/acp-11-38232011, 2011.

Clement, C. F., Kulmala, M., and Vesala, T.: Theoretical consideration on sticking probabilities, J. Aerosol Sci., 27, 869-882, doi:10.1016/0021-8502(96)00032-8, 1996.

Cleveland, W. S. and Devlin, S. J.: Locally Weighted Regression: An Approach to Regression Analysis by Local Fitting, J. Am. Stat. Assoc., 83, 596-610, doi:10.1080/01621459.1988.10478639, 1988.

Creamean, J. M., Ault, A. P., Ten Hoeve, J. E., Jacobson, M. Z., Roberts, G. C., and Prather, K. A.: Measurements of Aerosol Chemistry during New Particle Formation Events at a Remote Rural Mountain Site, Environ. Sci. Technol., 45, 8208-8216, doi:10.1021/es103692f, 2011.

Crilley, L. R., Ayoko, G. A., Jayaratne, E. R., Salimi, F., and Morawska, L.: Aerosol mass spectrometric analysis of the chemical composition of non-refractory PM1 samples from school environments in Brisbane, Australia, Sci. Total Environ., 458-460, 81-89, doi:10.1016/j.scitotenv.2013.04.007, 2013.

Crilley, L. R., Jayaratne, E. R., Ayoko, G. A., Miljevic, B., Ristovski, Z., and Morawska, L.: Observations on the Formation, Growth and Chemical Composition of Aerosols in an Urban Environment, Environ. Sci. Technol., 48, 6588-6596, doi:10.1021/es5019509, 2014.

Dal Maso, M., Kulmala, M., Riipinen, I., Wagner, R., Hussein, T., Aalto, P. P., and Lehtinen, K. E. J.: Formation and growth of fresh atmospheric aerosols: eight years of aerosol size distribution data from SMEAR II, Hyytiälä, Finland, Boreal Environ. Res., 10, 323-336, 2005.

Donaldson, K., Brown, D., Clouter, A., Duffin, R., MacNee, W., Renwick, L., Tran, L., and Stone, V.: The pulmonary toxicology of ultrafine particles, J. Aerosol Med., 15, 213-220, 2002.

Drewnick, F., Hings, S. S., DeCarlo, P., Jayne, J. T., Gonin, M., Fuhrer, K., Weimer, S., Jimenez, J. L., Demerjian, K. L., and Borrmann, S.: A new time-of-flight aerosol mass spectrometer
(TOF-AMS) - Instrument description and first field deployment, Aerosol Sci. Tech., 39, 637-658, 2005.

Ehn, M., Thornton, J. A., Kleist, E., Sipilä, M., Junninen, H., Pullinen, I., Springer, M., Rubach, F., Tillmann, R., Lee, B., LopezHilfiker, F., Andres, S., Acir, I. H., Rissanen, M., Jokinen, T., Schobesberger, S., Kangasluoma, J., Kontkanen, J., Nieminen, T., Kurtén, T., Nielsen, L. B., Jørgensen, S., Kjaergaard, H. G., Canagaratna, M., Maso, M. D., Berndt, T., Petäjä, T., Wahner, A., Kerminen, V. M., Kulmala, M., Worsnop, D. R., Wildt, J., and Mentel, T. F.: A large source of low-volatility secondary organic aerosol, Nature, 506, 476-479, 2014.

Everitt, B. S., Landau, S., Leese, M., and Stahl, D.: Cluster Analysis, 5 Edn., Wiley, Hoboken, 2010.

Fuks, N., Sutugin, A. G., and Soo, S.: Topics in current aerosol research, Pergamon Press, Oxford, 1971.

Hartigan, J. A. and Wong, M. A.: Algorithm AS 136: A K-Means Clustering Algorithm, J. Roy. Stat. Soc. C-App., 28, 100-108, doi:10.2307/2346830, 1979.

Hussein, T., Martikainen, J., Junninen, H., Sogacheva, L., Wagner, R., Dal Maso, M., Riipinen, I., Aalto, P. P., and Kulmala, M.: Observation of regional new particle formation in the urban atmosphere, Tellus B, 60, 509-521, doi:10.1111/j.16000889.2008.00365.x, 2008.

Jayne, J. T., Leard, D. C., Zhang, X., Davidovits, P., Smith, K. A., Kolb, C. E., and Worsnop, D. R.: Development of an aerosol mass spectrometer for size and composition analysis of submicron particles, Aerosol Sci. Tech., 33, 49-70, 2000.

Jimenez, J. L., Bahreini, R., Cocker, D. R., Zhuang, H., Varutbangkul, V., Flagan, R. C., Seinfeld, J. H., O'Dowd, C. D., and Hoffmann, T.: New particle formation from photooxidation of diiodomethane (CH2I2), J. Geophys. Res.-Atmos., 108, 21562202, doi:10.1029/2002JD002452, 2003a.

Jimenez, J. L., Jayne, J. T., Shi, Q., Kolb, C. E., Worsnop, D. R., Yourshaw, I., Seinfeld, J. H., Flagan, R. C., Zhang, X., and Smith, K. A.: Ambient aerosol sampling using the aerodyne aerosol mass spectrometer, J. Geophys. Res.-Atmos., 108, doi:10.1029/2001JD001213, 2003b.

Jimenez, J. L., Jayne, J. T., Shi, Q., Kolb, C. E., Worsnop, D. R., Yourshaw, I., Seinfeld, J. H., Flagan, R. C., Zhang, X., Smith, K. A., Morris, J. W., and Davidovits, P.: Ambient aerosol sampling using the Aerodyne Aerosol Mass Spectrometer, J. Geophys. Res.-Atmos., 108, 8425, doi:10.1029/2001JD001213, 2003c.

Kulmala, M., Kerminen, V.-M., Anttila, T., Laaksonen, A., and O'Dowd, C. D.: Organic aerosol formation via sulphate cluster activation, J. Geophys. Res.-Atmos., 109, D04205, doi:10.1029/2003JD003961, 2004.

Kulmala, M., Riipinen, I., Sipilä, M., Manninen, H. E., Petäjä, T., Junninen, H., Maso, M. D., Mordas, G., Mirme, A., Vana, M., Hirsikko, A., Laakso, L., Harrison, R. M., Hanson, I., Leung, C., Lehtinen, K. E. J., and Kerminen, V.-M.: Toward direct measurement of atmospheric nucleation, Science, 318, 89-92, 2007.

Kulmala, M., Kontkanen, J., Junninen, H., Lehtipalo, K., Manninen, H. E., Nieminen, T., Petäjä, T., Sipilä, M., Schobesberger, S., and Rantala, P.: Direct observations of atmospheric aerosol nucleation, Science, 339, 943-946, 2013.

Kulmala, M., Petäjä, T., Ehn, M., Thornton, J., Sipilä, M., Worsnop, D., and Kerminen, V.-M.: Chemistry of Atmospheric Nucleation: On the Recent Advances on Precursor Characterization and Atmospheric Cluster Composition in Connection with Atmospheric 
New Particle Formation, Annu. Rev. Phys. Chem., 65, 21-37, 2014a.

Kulmala, M., Petäjä, T., Ehn, M., Thornton, J., Sipilä, M., Worsnop, D. R., and Kerminen, V. M.: Chemistry of atmospheric nucleation: On the recent advances on precursor characterization and atmospheric cluster composition in connection with atmospheric new particle formation, Annu. Rev. Phys. Chem., 65, 21-37, 2014b.

Lehtinen, K. E. J., Korhonen, H., Dal Maso, M., and Kulmala, M.: On the concept of condensation sink diameter, Boreal Environ. Res., 8, 405-411, 2003.

Lohmann, U. and Feichter, J.: Global indirect aerosol effects: a review, Atmos. Chem. Phys., 5, 715-737, doi:10.5194/acp-5-7152005, 2005.

Mejía, J. F. and Morawska, L.: An investigation of nucleation events in a coastal urban environment in the Southern Hemisphere, Atmos. Chem. Phys., 9, 7877-7888, doi:10.5194/acp-9-7877-2009, 2009.

Modini, R. L., Ristovski, Z. D., Johnson, G. R., He, C., Surawski, N., Morawska, L., Suni, T., and Kulmala, M.: New particle formation and growth at a remote, sub-tropical coastal location, Atmos. Chem. Phys., 9, 7607-7621, doi:10.5194/acp-9-7607-2009, 2009.

Morawska, L., Wang, H., Ristovski, Z., Jayaratne, E. R., Johnson, G., Cheung, H. C., Ling, X., and He, C.: JEM Spotlight: Environmental monitoring of airborne nanoparticles, J. Environ. Monitor., 11, 1758-1773, doi:10.1039/B912589M, 2009.

Ng, N., Canagaratna, M., Jimenez, J., Zhang, Q., Ulbrich, I., and Worsnop, D.: Real-time methods for estimating organic component mass concentrations from aerosol mass spectrometer data, Environ. Sci. Technol., 45, 910-916, 2010a.

Ng, N. L., Canagaratna, M. R., Zhang, Q., Jimenez, J. L., Tian, J., Ulbrich, I. M., Kroll, J. H., Docherty, K. S., Chhabra, P. S., Bahreini, R., Murphy, S. M., Seinfeld, J. H., Hildebrandt, L., Donahue, N. M., DeCarlo, P. F., Lanz, V. A., Prévôt, A. S. H., Dinar, E., Rudich, Y., and Worsnop, D. R.: Organic aerosol components observed in Northern Hemispheric datasets from Aerosol Mass Spectrometry, Atmos. Chem. Phys., 10, 46254641, doi:10.5194/acp-10-4625-2010, 2010 b.

Ng, N. L., Canagaratna, M. R., Jimenez, J. L., Chhabra, P. S., Seinfeld, J. H., and Worsnop, D. R.: Changes in organic aerosol composition with aging inferred from aerosol mass spectra, Atmos. Chem. Phys., 11, 6465-6474, doi:10.5194/acp-11-64652011, 2011.

Ning, L., Sioutas, C., Cho, A., Schmitz, D., Misra, C., Sempf, J., Meiying, W., Oberley, T., Froines, J., and Nel, A.: Ultrafine Particulate Pollutants Induce Oxidative Stress and Mitochonrial Damage, Environ. Health Persp., 111, 455-460, 2003.

O’Dowd, C. D., Jimenez, J. L., Bahreini, R., Flagan, R. C., Seinfeld, J. H., Hämeri, K., Pirjola, L., Kulmala, M., Jennings, S. G., and Hoffmann, T.: Marine aerosol formation from biogenic iodine emissions, Nature, 417, 632-636, 2002.

Petäjä, T., Kerminen, V.-M., Dal Maso, M., Junninen, H., Koponen, I. K., Hussein, T., Aalto, P. P., Andronopoulos, S., Robin, D., Hämeri, K., Bartzis, J. G., and Kulmala, M.: Submicron atmospheric aerosols in the surroundings of Marseille and Athens: physical characterization and new particle formation, Atmos. Chem. Phys., 7, 2705-2720, doi:10.5194/acp-72705-2007, 2007.
Pirjola, L., Kulmala, M., Wilck, M., Bischoff, A., Stratmann, F., and Otto, E.: Formation of sulphuric acid aerosols and cloud condensation nuclei: an expression for significant nucleation and model comparison, J. Aerosol Sci., 30, 1079-1094, doi:10.1016/S00218502(98)00776-9, 1999.

Pope II, C. A. and Dockery, D. W.: Health effects of fine particulate air pollution: lines that connect, Air Waste Manage. Assoc., 56, 709-742, 2006.

Riccobono, F., Schobesberger, S., Scott, C. E., Dommen, J., Ortega, I. K., Rondo, L., Almeida, J., Amorim, A., Bianchi, F., Breitenlechner, M., David, A., Downard, A., Dunne, E. M., Duplissy, J., Ehrhart, S., Flagan, R. C., Franchin, A., Hansel, A., Junninen, H., Kajos, M., Keskinen, H., Kupc, A., Kürten, A., Kvashin, A. N., Laaksonen, A., Lehtipalo, K., Makhmutov, V., Mathot, S., Nieminen, T., Onnela, A., Petäjä, T., Praplan, A. P., Santos, F. D., Schallhart, S., Seinfeld, J. H., Sipilä, M., Spracklen, D. V., Stozhkov, Y., Stratmann, F., Tomé, A., Tsagkogeorgas, G., Vaattovaara, P., Viisanen, Y., Vrtala, A., Wagner, P. E., Weingartner, E., Wex, H., Wimmer, D., Carslaw, K. S., Curtius, J., Donahue, N. M., Kirkby, J., Kulmala, M., Worsnop, D. R., and Baltensperger, U.: Oxidation Products of Biogenic Emissions Contribute to Nucleation of Atmospheric Particles, Science, 344, 717-721, doi:10.1126/science.1243527, 2014.

Salimi, F., Mazaheri, M., Clifford, S., Crilley, L., Laiman, R., and Morawska, L.: Spatial variation of particle number concentration in school microscale environments and its impact on exposure assessment, Environ. Sci. Technol., 47, 5251-5258, doi:10.1021/es400041r, 2013.

Salimi, F., Ristovski, Z., Mazaheri, M., Laiman, R., Crilley, L. R., He, C., Clifford, S., and Morawska, L.: Assessment and application of clustering techniques to atmospheric particle number size distribution for the purpose of source apportionment, Atmos. Chem. Phys., 14, 11883-11892, doi:10.5194/acp-1411883-2014, 2014.

Salma, I., Borsós, T., Weidinger, T., Aalto, P., Hussein, T., Dal Maso, M., and Kulmala, M.: Production, growth and properties of ultrafine atmospheric aerosol particles in an urban environment, Atmos. Chem. Phys., 11, 1339-1353, doi:10.5194/acp-111339-2011, 2011.

Stanier, C. O., Khlystov, A. Y., and Pandis, S. N.: Nucleation Events During the Pittsburgh Air Quality Study: Description and Relation to Key Meteorological, Gas Phase, and Aerosol Parameters Special Issue of Aerosol Science and Technology on Findings from the Fine Particulate Matter Supersites Program, Aerosol Sci. Tech., 38, 253-264, 2004.

Stevens, B. and Feingold, G.: Untangling aerosol effects on clouds and precipitation in a buffered system, Nature, 461, 607-613, 2009.

WHO, W. H. O.: Air Quality Guidelines: Global Update 2005: Particulate Matter, Ozone, Nitrogen Dioxide, and Sulfur Dioxide, World Health Organization Europe, 2005.

Willeke, K.: Temperature dependence of particle slip in a gaseous medium, J. Aerosol Sci., 7, 381-387, doi:10.1016/00218502(76)90024-0, 1976.

Woo, K., Chen, D., Pui, D., and McMurry, P.: Measurement of Atlanta aerosol size distributions: observations of ultrafine particle events, Aerosol Sci. Tech., 34, 75-87, 2001.

Zhang, Q., Stanier, C. O., Canagaratna, M. R., Jayne, J. T., Worsnop, D. R., Pandis, S. N., and Jimenez, J. L.: Insights into 
the Chemistry of New Particle Formation and Growth Events in Pittsburgh Based on Aerosol Mass Spectrometry, Environ. Sci.

Technol., 38, 4797-4809, doi:10.1021/es035417u, 2004. 